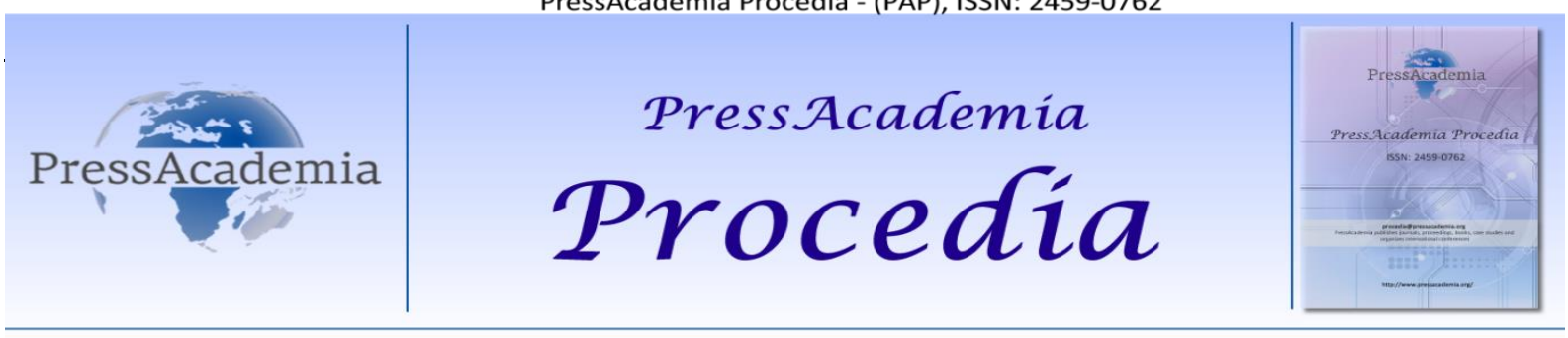

Global Business Research Congress (GBRC), May 24-25, 2017, Istanbul, Turkey.

\title{
ORGANIZATIONAL AMBIDEXTERITY IN SMES IN TURKEY: COMBINATION OF CONFLICTING ORGANIZATIONAL STRATEGIES
}

\section{DOI: 10.17261/Pressacademia.2017.668}

PAP- GBRC-V.3-2017(95)-p.875-878

\section{Harun Yildiz ${ }^{1}$, Gulbey Karatas ${ }^{2}$}

${ }^{1}$ Kafkas University, Department of Management, Central Campus, 36100, Kars, Turkey. dryildizharun@gmail.com

${ }^{2}$ Ağrı İbrahim Çeçen University, Vocational School, Ağrı, Turkey. gulbeykaratas1@gmail.com

To cite this document

Yildiz, H. and G. Karataş, (2017). Organizational ambidexterity in SMEs in Turkey: combination of conflicting organizational strategies. PressAcademia Procedia (PAP), V.3, p.875-878.

Permemant link to this document: http://doi.org/10.17261/Pressacademia.2017.668

Copyright: Published by PressAcademia and limited licenced re-use rights only.

\begin{abstract}
The aim of this study is to determine the level of organizational ambidexterity in terms of small and medium enterprises (SMEs) and to detect how many SMEs are involved in the ambidextrous group in Turkey. Data was collected with using convenience sampling method from managers working in different sectors in Turkey. The data were analyzed using IBM SPSS 21.0. Findings revealed that approximately $50 \%$ of SMEs (298 enterprises) are the high-level ambidexterity. Ambidexterity means to an organization's ability to pursue both exploitative and exploratory orientation. Ambidextrous organizations can use exploitative and exploratory strategies concurrently. Accordingly, in today's business world where change, environmental uncertainty, and sustainable competitive advantage are important, organizational ambidexterity provides organizations adaptability capabilities. Also, this study provides theoretical and practical implications for further research.
\end{abstract}

Keywords: Organizational ambidexterity, exploitation, exploration, clustering analysis, SMEs.

JEL Codes: M10, M16, M19

\section{TÜRKIYE'DEKI KOBi'LERDE ÖRGÜTSEL USTALIK: ÇATIŞAN STRATEJILERIN BİRLEŞIMI}

\section{ÖZET}

Bu araştırmanın amacı, küçük ve orta ölçekli işletmeler (КОВі) açısından örgütsel ustalık düzeyini belirlemek ve bu işletmelerin ne kadarının usta düzeyindeki işletmeler arasında yer aldığını tespit etmektir. Araştırma verileri Türkiye'deki farklı sektörlerdeki yöneticilerden kolayda örnekleme yöntemi ile toplanmıştır. Araştırma verileri IBM SPSS 21.0 ile analiz edilmiştir. Bulgular araştırma kapsamındaki KOBi’lerin yaklaşık olarak \%50'sinin yüksek düzeyde ustalık düzeyine sahip olduğunu göstermektedir. Örgütsel ustalık bir organizasyonun hem yararlanıcı hem de araştırıcı iki faklı stratejiyi eş zamanlı takip edebilme becerisidir. Değişim, belirsizlik ve sürdürülebilir rekabet üstünlüğünün önem kazandığı günümüz iş dünyasında, bu beceri örgütlere ihtiyaç duyulan uyarlanabilirlik yeteneklerini sağlamaktadır. Aynı zamanda bu araştırma gelecekteki araştırmalar için teorik ve pratik uygulamalar sunmaktadır.

Anahtar Kelimeler: Örgütsel ustalık, yararlanma, araştırma, kümeleme analizi, KOBi.

JEL Kodları: M10, M16, M19 


\section{GíRiş}

Bulundukları ülkelerdeki ekonomilerin temel ve dinamik yapı taşlarını oluşturan küçük ve orta ölçekli işletmeler (KOBi'ler), faaliyet gösterdikleri pazarlarda rekabetin sürdürülebilmesini sağlamaktadır. KOBi’lerle büyük şehirlerden uzakta olan taşra ekonomilerinde sıklıkla karşılaşılmaktadır (Top vd., 2014: 24). Kobiler istihdamın sağlanmasına, sektörel kalkınmışığın gelişmesine ve ülke ekonomilerinin canlanmasına olumlu yönde etki yapmaktadır. KOBi'lerin faaliyetlerine devam etmeleri yapmış oldukları yenilikçi, yaratıcı, üretici ve mevcut kaynaklarla karşılaşılan fırsatları değerlendirici stratejilere sahip olmalarıyla mümkün olmaktadır. Yazında araştırıcı ve yararlanıc stratejiler olarak ifade edilen bu stratejiler aslında birbirinden tamamen farklı birer stratejilerdir. Ancak bu stratejileri işletmeler bir arada da uygulayabilmektedirler. Örgütlerin hem araştırıcı hem de yaralanıcı stratejileri aynı anda kullanabilme yeteneğine sahip olmaları o örgütlerin usta örgüt olduklarını ifade etmektedir. Örgütsel ustalık yeteneğinin araştırıcı ve yaralanıcı yetenekleri "örgütsel ustalığın temel göstergeleri" olarak belirtilmektedir (Li, Lin ve Chu, 2008). Bu kapsamda yapılan araştırmanın amacı KOBi'lerin Türkiye ekonomisindeki öneminin ortaya konulması ve Türkiye' de faaliyet gösteren ve araştırma kapsamında incelenen KOBi'lerdeki örgütsel ustalık düzeyinin belirlenmesidir.

\section{LITERATÜR INCELEMESI}

\subsection{Küçük ve Orta Ölçekli İşletmelerin Ekonomideki Önemi}

Küresel düzeydeki etkileşimlerin sıklıkla yaşandığı günümüzde işletmelerin büyük bir çoğunluğu küçük ve orta ölçekli işletmelerden (KOBi'ler) oluşmaktadır. KOBi'ler esnek ve dinamik yapılarıyla ülke ekonomilerinin vazgeçilmez unsurları olarak ön plana çıkmaktadır. KOBi'ler bölgesel gelişmeye olumlu yönde etki etmekte ve kalkınmayı hızlandırmaktadırlar. Aynı zamanda emek-yoğun özelliğine sahip olmaları nedeniyle de KOBi'ler bölgesel kalkınmanın ve istihdamın artmasına katkı sağlamaktadırlar (Sarıaslan, 1995).

Türkiye ekonomisinde önemli bir rol üstlenen KOBi'ler faaliyet göstermiş oldukları sektörlerin can damarları olma konumundadır. Son yıllarda ekonomide meydana gelen küresel etkileşimin artması, Türkiye'de faaliyet gösteren KOBi'lerin daha farklı özelliklere sahip olmalarını gerekli kılmıştır. KOBi'leri birbirinden farklı kılan bu özelliklerden biri de işletmelerin örgütsel ustalık yeteneğine sahip olup olmadıklarıdır. Bu kapsamda KOBi’lerin sürdürülebilir rekabet üstünlüğünü olumlu yönde etkileyebilen örgütsel ustalık yeteneği aşağıda detaylı olarak açıklanmıştır.

\section{2. Örgütsel Ustalık}

Bodwell ve Chermack (2010) örgütsel ustalığı, örgütlerin daha önceden belirlemiş oldukları stratejileri ve karşılaşılan yeni yaklaşımları bir arada kullanabilme yeteneği olarak tanımlamaktadır. Diğer bir tanıma göre ise örgütsel ustalık, işletmelerin ürünler, piyasa ve teknolojik gelişmeler arasında uzun dönemli uyum sağlayabilme, kısa dönemli karlılık ve sürdürülebilir koordinasyon yeteneklerine sahip olmaları olarak tanımlanmaktadır (Chaharmahali ve Siadat, 2010: 6-7). Iş̧letmelerin birbirinden farklı araştırıcı ve yaralanıcı stratejileri bir arada kullanabilme yeteneklerine örgütsel ustalık denmektedir (Akdoğan, Akdoğan ve Cingöz, 2009; Cingöz ve Akdoğan, 2015: 59).

Örgütsel ustalık yeteneğine sahip olan işletme yöneticileri hem araştırıcı hem de yararlanıcı olmaktadır. Araştırıcı örgütsel ustalık becerisi olan yöneticiler gelişen teknolojiler, yeni pazarlar, ortaya çıkan farklııklar ve fırsatların araştırılmasını sağlayan kişilerdir. Bu tip yöneticiler risk alma, yenilikçilik, esneklik, çeşitlilik gibi özelliklere sahip bireylerdir (He ve Wong, 2004; Cingöz ve Akdoğan, 2015). Yararlanıcı örgütsel ustalık becerisine sahip yöneticiler ise elde edilen bilgilerin, teknolojik imkânların ve pazarlama yöntemlerinin verimli bir şekilde nasıl kullanılacağını belirleyen kişilerdir. Bu tip yöneticiler üretici, etkin, geliştirici, seçici ve uygulayıcı gibi özelliklere sahip bireylerdir (He ve Wong, 2004: 481). Örgütsel ustalık bağlamında işletmelerin araştırıcı ve yaralanıı örgütsel ustalık stratejilerinden etkinlik ve verimlilik elde edebilmeleri için her iki stratejik süreci birbiri ile orantılı olarak yönetmeleri gerekmektedir (Tan ve Liu, 2014: 424). İşletmeler örgütsel yapılarını, araştırıcı ve yararlanıc örgütsel ustalık stratejilerini aynı anda uygulayabilecek şekilde düzenlemeleri sonucunda, üst düzey usta olabilmektedir.

\section{VERI VE YÖNTEM}

Yapılan çalışmada veriler anket yoluyla elde edilmiştir. Araştırmanın örneklemini Doğu Anadolu Bölgesinde bulunan 600 işletme oluşturmaktadır. Çalışmada Lubatkin ve arkadaşlarının (2006) geliştirdikleri ve Cingöz ve Akdoğan'ın (2015) çalışmalarında kullandıkları on iki ifadeden oluşan 5'li likert ölçeği kullanılmıştır (1-Kesinlikle katılmıyorum, 5-Kesinlikle katılıyorum). Araştırma verileri kümeleme ve korelasyon analiz yöntemleri kullanılarak açıklanmıştır. Yapılan korelasyon analizi ile değişkenler arasındaki birlikte değişim ilişkisi ortaya konulmuştur. Araştırıcı ustalık stratejisini ölçen ölçeğin güvenirlik katsayısı $0.822^{\prime}$ dir. Yararlanıcı ustalık stratejisini ölçen ölçeğin güvenirlik katsayısı $0.775^{\prime}$ tir. Örgütsel ustalık ölçeğinin genel olarak güvenirlik kat sayısı ise 0.871 'dir. Kümeleme analizi birbirine benzer olan gözlemleri bir araya getirmekte ve her kümeyi oluşturan gözlemlerin değişkenlere göre ortalamalarını vermektedir. Yapılan kümeleme analizi 
araştırma kapsamında değerlendirilen 600 işletmeden 298 (yaklaşık olarak \%50) işletmenin örgütsel ustalık düzeyinde olduğunu göstermektedir.

\section{BULGULAR VE TARTIŞMA}

Örgütsel ustalık seviyesini artırmak isteyen işletmeler çevrenin işletmeye olan etkilerini iyi belirlemeli, ustalık için gereken koşulları belirleyip iyi analiz etmeli ve geliştirmelidir. Ayrıca örgütsel ustalık stratejileri sadece işletme yöneticileri tarafından değil, çalışanlar tarafından da benimsenmelidir. Örgütsel ustalığın ön plana çıkması için çevresel şartların da (rekabet ve çevresel hareketlilik) uygun olması ve çevresel şartların benimsenen stratejiyi destekler nitelikte olması gerekmektedir (Kriz vd., 2014; Cingöz ve Akdoğan, 2015). Örgütsel ustalık düzeyine ulaşmak isteyen işletmeler, ustalığı belirleyen etkenlerin neler olduklarını iyice araştırmaları ve belirlemiş oldukları koşulları geliştirmeleri gerekmektedir (March, 1991; Floyd ve Lane, 2000).

\section{SONUÇ}

Örgütsel ustalık yeteneğine sahip olan işletmeler, birbirinden farklı olan ve birbiriyle çatışan stratejileri aynı anda kullanabilmektedir. Yazında yer alan birçok da çalışma örgütsel ustalığı bu yönüyle ele almaktadır (March, 1991; Floyd ve Lane, 2000; Benner ve Tushman, 2003; Birkinshaw ve Gibson, 2004; Kriz vd., 2014; Hodgkinson vd., 2014; Fındıklı ve Pınar, 2014; Cingöz ve Akdoğan, 2015; Erşahan vd., 2015). Yapılan bu çalışmanın sonucu da daha önce yapılan çalışmaları destekler niteliktedir (Birkinshaw ve Gibson, 2004; Cingöz ve Akdoğan, 2015). Örgütsel ustalık düzeyine ulaşan işletmeler sahip oldukları araştıııcı ve yararlanıcı yeteneklerini etkin ve verimli bir şekilde kullanarak değişen çevresel koşullara uyum sağlamakta, pazara hâkim olmakta ve sürdürülebilir rekabet üstünlüğünü devam ettirmektedir (Cingöz ve Akdoğan, 2015). Örgütsel ustalık yeteneğine sahip olan işletmeler, araştırıcı ustalık yeteneği ile yeni piyasaları, teknolojik gelişmeleri ve yeni kaynakları araştırırken aynı zamanda da yararlanıcı ustalık yeteneğiyle de mevcut kaynak ve yeteneklerini geliştirmektedir (March, 1991). Bu çalışmada örneklem kapsamında ele alınan 600 işletmenin 298'i (yaklaşık \%50) araştırıcı ve yararlanıcı ustalık yeteneklerini aynı anda uygulayabilen örgütsel ustalık düzeyine ulaşmış işletmelerdir. Yapılan araştırmalar sonucunda da sürdürülebilir rekabet üstünlüğüne sahip olan ve faaliyet gösterdikleri pazarları yönlendiren işletmelerin araştırıcı ve yararlanıcı ustalık stratejilerini bir arada ve birbiri ile uyumlu olarak kullanabildikleri gözlenmektedir. Bu anlamda işletmelerin/yöneticilerin bu stratejik bilinçle hareket etmeleri son derece önemlidir (Bayarçelik, Özşahin ve Yıldız 2017).

\section{KAYNAKLAR}

Akdoğan, Ş., Akdoğan, A. ve Cingöz, A. (2009). Organizational ambidexterity: An empirical examination of organizational factors as antecedents of organizational ambidexterity. Journal of Global Strategic Management, 3(2): 17-27.

Bayarçelik E. B., Özşahin, M. ve Yıldız, B. (2017). Strateji tipleri ile yenilik performansı ilişkisinde stratejik karar verme hızının şartlı değişken (moderator) etkisi. 16. Ulusal İşletmecilik Kongresi, 4 Mayıs-6 Mart, İzmir.

Benner, M. J. ve Tushman, M. L. (2003). Exploitation, exploration, and process management: The productivity dilemma revisited. Academy of Management Review, 28(2): 238-256.

Birkinshaw, J. ve Gupta, K. (2013). Clarifying the distinctive contribution of ambidexterity to the field of organization studies. The Academy of Management Perspectives, 27(4): 287-298.

Bodwell, W. ve Chermack, T. J. (2010). Organizational ambidexterity: Integrating deliberate and emergent strategy with scenario planning. Technological Forecasting and Social Change, 77(2): 193-202.

Chaharmahali, S. M. ve Siadat, A. S. (2010). Achieving organizational ambidexterity (Understanding and explaining ambidextrous organizations). Linköping University Department of Menegement and Engineering Strategic Management, Unpublished Doctoral Dissertation, Sweden.

Cingöz, A. ve Akdoğan, A. A. (2015). Örgütsel ustalık (organizational ambidexterity): Örgütsel ustalık düzeyini belirlemede araştırıcı ve yararlanıcı stratejilerin etkileşimsel rolü. Aksaray Üniversitesi İktisadi ve İari Bilimler Fakültesi Dergisi, 7(1): 59-67.

Erşahan, B., Büyükbeşe, T., Bakan, İ. ve Sezer, B. (2015). Örgütsel ustalık. Bakan, İ. (Ed.). Çağdaş yönetim yaklaşımları (s. 613-627). İstanbul: Beta Yayınları

Fındıklı, M. A. ve Pınar, İ. (2014). Örgüt kültürü algısı ve örgütsel çift yönlülük ilişkisi: örgütsel düzeyde bilgi paylaşımının aracılık etkisi. Yönetim ve Ekonomi: Celal Bayar Üniversitesi Iktisadi ve Idari Bilimler Fakültesi Dergisi, 21(1): 155-171.

Floyd, S. W. ve Lane, P. J. (2000). Strategizing throughout the organization: Managing role conflict in strategic renewal. Academy of Management Review, 25(1): 154-177.

He, Z. L. ve Wong P.K. (2004). Exploration vs. exploitation: an empirical test of the ambidexterity hypothesis. Organization Science, 15(4): 481-494. 
Hodgkinson, I. R., Ravishankar, M. N. ve Aitken-Fischer, M. (2014). A resource-advantage perspective on the orchestration of ambidexterity. The Service Industries Journal, 34(15): 1234-1252.

Kriz, A., Voola, R. ve Yüksel, U. (2014). The dynamic capability of ambidexterity in hypercompetition: qualitative insights. Journal of Strategic Marketing, 22(4): 287-299.

Li, C. R., Lin, C. J. ve Chu, C. P. (2008). The nature of market orientation and the ambidexterity of innovations. Management Decision, 46(7): 1002-1026.

Lubatkin, M. H., Simsek, Z., Ling, Y. ve Veiga, J. F. (2006). Ambidexterity and performance in small-to medium-sized firms: The pivotal role of top management team behavioral integration. Journal of Management, 32(5): 646-672.

March, J. G. (1991). Exploration and exploitation in organizational learning. Organization Science, 2(1): 71-87.

Sarıaslan, H. 1995. Küçük ve orta ölçekli işletmelerin finansmanı için yeni model önerileri. Ankara Üniversitesi Siyasal Bilgiler Fakültesi Dergisi, 50(1): 313-321.

Tan, M. ve Liu, Z. (2014). Paths to success: An ambidexterity perspective on how responsive and proactive market orientations affect SMEs' business performance. Journal of Strategic Marketing, 22(5): 420-441.

Top, Y., Adanur, H., Öz, M. ve Yaşar, M. (2014). Gümüşhane ili orman ürünleri sanayi işletmelerinin yapısal özelliklerinin incelenmesi. Journal of Forestry Faculty of Kastamonu University, 14(1): 24-36. 